\title{
Changing the idiopathic pulmonary fibrosis treatment approach and improving patient outcomes
}

\section{Vincent Cottin}

ABSTRACT: Idiopathic pulmonary fibrosis (IPF) is a progressively fibrotic disease, with no effective treatment and a median survival time of 2-5 yrs. The search for effective treatment has involved numerous clinical trials of investigational agents without significant success until 2011, when European approval was given for the first treatment for IPF, pirfenidone. Four key clinical trials supported the efficacy and tolerability of pirfenidone.

In recently published results from two phase III randomised, double-blind, placebo-controlled, multinational trials evaluating pirfenidone (studies 004 and 006), patients with mild-to-moderate IPF were screened for eligibility using the following functional criteria: forced vital capacity (FVC) $\geqslant 50 \%$ predicted; diffusing capacity of the lung for carbon monoxide $\geqslant 35 \%$; and 6 -min walk test (6MWT) distance $\geqslant 150 \mathrm{~m}$.

Only study 004 met the primary end-point of change in per cent predicted FVC at week 72 $(p<0.001)$. Pooled analysis of primary end-point data from both studies also showed that pirfenidone significantly reduced the decline in per cent predicted FVC compared to placebo $(p<0.005)$. Evidence of beneficial effects of pirfenidone treatment was also observed with regard to several secondary end-points, including progression-free survival time, categorical FVC change, and mean change from baseline to week 72 in 6MWT distance.

Pirfenidone was generally well tolerated, with the most common side-effects being gastrointestinal discomfort and photosensitivity. The pooled study results, coupled with recent data regarding the prognostic significance of changes in FVC and 6MWT, provide further evidence of a clinically meaningful treatment benefit with pirfenidone in patients with IPF.

KEYWORDS: Forced vital capacity, idiopathic pulmonary fibrosis, pirfenidone

I diopathic pulmonary fibrosis (IPF) is a progressive and fatal fibrotic lung disease with a median survival of $2-5$ yrs. This debilitating disease occurs predominantly in older adults, with an estimated prevalence of 1.6 to 1.7 per $10,000[1,2]$. Progressive deterioration of pulmonary function is inevitable, which increasingly limits the normal physical activity of the patient $[3,4]$. The pace and magnitude of disease progression is often unpredictable [5], with apparently stable patients often suffering episodes of acute exacerbation $[6,7]$.

\section{PROGNOSTIC FACTORS}

Pulmonary function test values are often used as predictive factors of survival in IPF. A decline in forced vital capacity (FVC) has consistently been shown to be a strong predictor of mortality, and is frequently used as an end-point in clinical trials $[8,9]$. A decline in FVC of $\geqslant 10 \%$ in a 6-month period is associated with a nearly five-fold increase in the risk of mortality [9-12]. Indeed, agents that attenuate the decline in FVC are anticipated to play an important role in the management of patients with IPF.

Other prognostic factors commonly used as endpoints in IPF clinical trials include: diffusing capacity of the lung for carbon monoxide (DL,CO), a decrease of $15 \%$ of the absolute value has been associated with increased risk of mortality [10, 13-15]; a change in alveolar-arterial oxygen tension difference of $>15 \mathrm{mmHg}$ after 12 months has been shown to be predictive of survival [10, $14]$; the 6-min walk test (6MWT), which has been
CORRESPONDENCE V. Cottin

Hôpital Louis Pradel Service de Pneumologie 28 Avenue Doyen Lepine 69677 Lyon

France

E-mail: vincent.cottin@chu-lyon.fr

Received:

Feb 032012

Accepted after revision:

Feb 212012

\section{PROVENANCE}

Publication of this peer-reviewed article was sponsored by InterMune International AG, Muttenz, Switzerland (article sponsor, European Respiratory Review issue 124). 
widely used in clinical practice, a shorter walk distance and delayed heart rate recovery after 6MWT have been associated with an increased risk of mortality [8, 10, 16-19].

\section{THE SEARCH FOR NEW THERAPIES AND RECENTLY COMPLETED TRIALS}

Since 2001, the search for new therapies to treat IPF has intensified, as demonstrated by an increase in the number of registered clinical trials. However, many of these clinical trials have failed to demonstrate a statistically significant treatment effect on the primary end-point [20].

In 2005, results were published from the IFIGENIA (Idiopathic Pulmonary Fibrosis International Group Exploring $\mathrm{N}$-Acetylcysteine I Annual) trial, which was conducted to investigate whether a high dose of $\mathrm{N}$-acetylcysteine (NAC), administered over the course of $1 \mathrm{yr}$ to patients receiving treatment with prednisone and azathioprine, would slow the functional deterioration in patients with IPF [21]. This was a double-blind, randomised, placebo-controlled, multicentre study with primary end-points of absolute changes in vital capacity (VC) and DL,CO between baseline and 12 months. The trial showed that patients receiving prednisone, azathioprine and NAC for 12 months had a significantly slower rate of deterioration of both $\mathrm{VC}$ and $\mathrm{DL}, \mathrm{CO}$ than the patients who received only prednisone and azathioprine therapy, suggesting that the addition of NAC could aid preservation of pulmonary function in patients with IPF. There is, however, considerable uncertainty about the clinical relevance of this result due to a drop-out rate of $\sim 30 \%$ and the absence of a suitable control arm [20, 21].

The potential benefit of NAC and triple combination therapy (prednisolone, azathioprine and NAC) is currently being evaluated in the PANTHER (Prednisone, Azathioprine, $N$-acetylcysteine, a Trial tHat Evaluates Response) trial coordinated by the National Heart, Lung and Blood Institute (Bethesda, MD, USA). However, on October 21, 2011 a press release was published announcing that the triple therapy arm of this trial had been discontinued due to an excess of deaths or emergency hospitalisations, and a higher prevalence of serious adverse events compared with the comparative arms of placebo and NAC alone [22]. As the trial is continuing with the NAC and placebo arms, the detailed results of this study are not yet known. However, the triple therapy cannot be considered a standard therapy in patients with IPF [22, 23], and the potential benefit of NAC requires further evaluation.

A recent phase II trial assessed the efficacy and safety of four different oral doses $(50 \mathrm{mg}$ q.d., $50 \mathrm{mg}$ b.i.d., $100 \mathrm{mg}$ b.i.d. or $150 \mathrm{mg}$ b.i.d.) of the tyrosine kinase inhibitor BIBF 1120 compared to placebo in 432 patients with IPF. The primary end-point was the annual rate of decline in FVC [24]. Secondary end-points included acute exacerbations, quality of life (measured with the St George's Respiratory Questionnaire (SGRQ)) and total lung capacity. The predefined, multiplicity-corrected primary end-point did not differ significantly between the group of patients receiving the highest BIBF 1120 dose (150 mg b.i.d.) and the placebo group. The annual rate of decline in FVC in the group receiving $150 \mathrm{mg}$ of BIBF 1120 b.i.d. was $0.06 \mathrm{~L}$ (95\% CI -0.14-0.02 L), as compared with $0.19 \mathrm{~L}$ in the placebo group $(95 \% \mathrm{CI}$
$-0.26--0.12 \mathrm{~L})(\mathrm{p}=0.06$ with the closed testing procedure for multiplicity; $p=0.01$ with hierarchical testing) [24]. The incidence of acute exacerbations was $2.4 \%$ per 100 patient-yrs in patients receiving $150 \mathrm{mg}$ of BIBF 1120 b.i.d. and 15.7\% per 100 patient-yrs in the placebo group $(\mathrm{p}=0.02)$. A nonsignificant decrease in the SGRQ was observed. Treatment was discontinued by $30.6 \%$ of patients receiving BIBF 1120 at $150 \mathrm{mg}$ b.i.d. and by $25.9 \%$ of patients receiving placebo. Further studies are required to evaluate the potential benefit of BIBF 1120 in reducing the decline in lung function [24].

Numerous other targets have been explored in an attempt to find an effective treatment for IPF. Bosentan is a dual endothelin receptor antagonist, and is an effective treatment for pulmonary arterial hypertension, a disease characterised by progressive remodelling of the pulmonary vasculature [25]. Due to its anti-inflammatory and anti-fibrotic properties, it was suggested that bosentan might be potentially useful in the treatment of IPF. However, bosentan was not found to be superior to placebo in terms of 6MWT distance (primary endpoint) in the BUILD-1 (Bosentan Use in Interstitial Lung Disease) study. A trend was observed in favour of bosentan for the secondary end-point of time to death or disease progression, and this was more pronounced in patients with IPF diagnosed by surgical lung biopsy [25]. A further study, BUILD-3, used the primary end-point of time to disease worsening or death but found no significant difference compared with placebo [26]. Taken together, the results of these two studies suggest that bosentan is unlikely to be of benefit to IPF patients.

Imatinib mesylate is another agent that has been investigated for the potential treatment of IPF. As imatinib mesylate is a tyrosine kinase inhibitor with activity against platelet-derived growth factor receptor, it was considered that this may be a useful agent in IPF treatment [27]. However, a phase II study of 119 patients with IPF found no significant benefit of treatment with imatinib mesylate compared with placebo in terms of the primary end-point of time to disease progression. No effects on lung function were observed, and it was concluded that imatinib mesylate is not an effective therapy for patients with IPF [27].

Another potential approach is the use of a phosphodiesterase type- 5 inhibitor, such as sildenafil, which has been shown to preferentially improve pulmonary ventilation [28]. Despite the suggestion that sildenafil may also have beneficial effects for patients with IPF, a phase III study found that sildenafil treatment did not improve 6MWT distance compared with placebo. Small improvements were seen in the extent of dyspnoea and quality of life in favour of sildenafil. These were considered clinically significant, with the investigators suggesting that sildenafil may have some use in improving symptoms for patients with advanced IPF [28].

The presence of elevated levels of tumour necrosis factor (TNF) $\alpha$ in models of pulmonary fibrosis provided rationale for the investigation of etanercept for the treatment of IPF [29]. RAGHU et al. [29] designed an exploratory placebo-controlled trial to determine whether etanercept had a positive effect on declining lung function compared with placebo in IPF patients. Although etanercept was well tolerated, no statistically 
significant differences were observed in lung function parameters, although this study recruited only a small number of patients $(n=88)$.

KING et al. [30] studied the use of interferon- $\gamma 1 \mathrm{~b}$ in a phase III study of patients with IPF. The primary end-point of this study was improvement in overall survival versus placebo. At the second interim analysis of this study, the required minimum benefit had not been demonstrated, and so the study was stopped. The authors reported that this study conclusively demonstrated a lack of improvement in overall survival of IPF patients with interferon- $\gamma 1 \mathrm{~b}$ [30].

Despite few positive outcomes, the results of these studies showed that randomised, controlled trials are feasible in investigating potential new treatments for this progressive disease.

\section{Pirfenidone for the treatment of mild-to-moderate IPF}

Pirfenidone (5-methyl-1-phenyl-2-[1H]-pyridone) is an orally administered drug that has exhibited anti-fibrotic and antiinflammatory properties in a variety of in vitro and in vivo studies [31-35]. There is evidence to show that pirfenidone mitigates fibroblast proliferation, fibrosis-associated proteins and cytokines (transforming growth factor- $\beta$ and plateletderived growth factor), biosynthesis and accumulation of extracellular matrix, as well as accumulation of inflammatory cells and TNF- $\alpha$ synthesis [31-35].

Pirfenidone was approved by the European Commission in February 2011 following evaluation in one phase II and three phase III clinical trials in patients with IPF [36-38]. Pirfenidone is indicated for the treatment of mild-to-moderate IPF patients. Mild-to-moderate disease was characterised in the pivotal phase III studies by the following functional criteria: FVC $\geqslant 50 \%$ of predicted, $D \mathrm{~L}, \mathrm{CO} \geqslant 35 \%$ pred and a $6 \mathrm{MWT}$ distance of $\geqslant 150 \mathrm{~m} \mathrm{[38].}$

\section{Phase III trial of Japanese patients}

Based on a positive phase II study [36], a multicentre, doubleblind, placebo-controlled, randomised phase III clinical trial to determine the efficacy and safety of pirfenidone in 275 patients with IPF was conducted in Japan over a period of 52 weeks [37]. Patients were randomised to receive pirfenidone $1,800 \mathrm{mg} \cdot \mathrm{day}^{-1}$, pirfenidone $1,200 \mathrm{mg} \cdot \mathrm{day}^{-1}$ or placebo in the ratio of $2: 1: 2$, with 267 patients being evaluated for the efficacy of pirfenidone. The dose of pirfenidone was increased in a stepwise manner up to the treatment dose over 4 weeks. The primary end-point was revised to change in VC from baseline to 52 weeks before unblinding of the study (the primary end-point was previously arterial oxygen saturation measured by pulse oximetry $\left(\mathrm{Sp}, \mathrm{O}_{2}\right)$ during the 6-min steady-state exercise test). The decision to revise the primary end-point was based on the evolved knowledge of assessment with objective measurements in IPF, as well as the lack of validation in the study of the steady-state exercise test and problems in reproducing $\mathrm{Sp}, \mathrm{O}_{2}$ measurements during the $6 \mathrm{MWT}$. Secondary end-points included progression-free survival (defined as the time until the first progressive event, i.e. either decrease in VC of $>10 \%$ or death) and change in the lowest $S \mathrm{p}, \mathrm{O}_{2}$ during the 6-min steady-state exercise test [37].

This study found significant differences between the pirfenidone $1,800 \mathrm{mg} \cdot$ day $^{-1}$ group and the placebo group for both the primary (decline in VC) and secondary progression-free survival end-points. There was a $44 \%$ reduction in the VC decline in favour of pirfenidone compared with placebo (change in VC: pirfenidone -0.09 L and placebo -0.16 L; $p=0.0416$ ) (fig. 1). Pirfenidone was also associated with a significant increase in progression-free survival $(p=0.0280)$. With regard to safety, pirfenidone was relatively well tolerated. The most common adverse event observed in both the high- and low-dose pirfenidone groups was photosensitivity $(51 \%$ and $53 \%$, respectively), which was rated as mild in the majority of patients [37], and has been documented as a side-effect associated with pirfenidone in previous studies [36, 39]. The data from this phase III trial led to the approval of pirfenidone for IPF patients in Japan in 2008.

\section{Multinational phase III trials 004 and 006: CAPACITY programme}

Pirfenidone has been studied in two concurrent, similar phase III trials (studies 004 and 006), which were conducted at 110 sites across North America, Australia and Europe. Both trials were randomised, double-blind, placebo-controlled studies with a treatment period of 72 weeks. The studies were designed to confirm the results of a phase II study suggesting that pirfenidone reduces the deterioration in lung function in patients with IPF [38]. The data from these two phase III trials led to the approval of pirfenidone for IPF patients in the European Union in 2011.

Eligible patients were aged $40-80$ yrs with a confident diagnosis of IPF in the previous 48 months and no evidence of improvement in measures of disease severity over the preceding year. Additional criteria for enrolment included: an FVC of $\geqslant 50 \%$ pred; $D \mathrm{~L}, \mathrm{CO} \geqslant 35 \%$ pred; FVC or $D \mathrm{~L}, \mathrm{CO}$ of $\leqslant 90 \%$ pred; and a $6 \mathrm{MWT}$ distance of $\geqslant 150 \mathrm{~m}$. For patients aged $>50 \mathrm{yrs}$ and those not meeting the protocol criteria for definite IPF by use of highresolution computed tomography, a lung biopsy sample showing usual interstitial pneumonia was required [38].

In study 004, patients were assigned to oral pirfenidone $2,403 \mathrm{mg} \cdot \mathrm{day}^{-1}$ or $1,197 \mathrm{mg} \cdot \mathrm{day}^{-1}$, or placebo in a 2:1:2 ratio, while in study 006, patients were assigned to pirfenidone

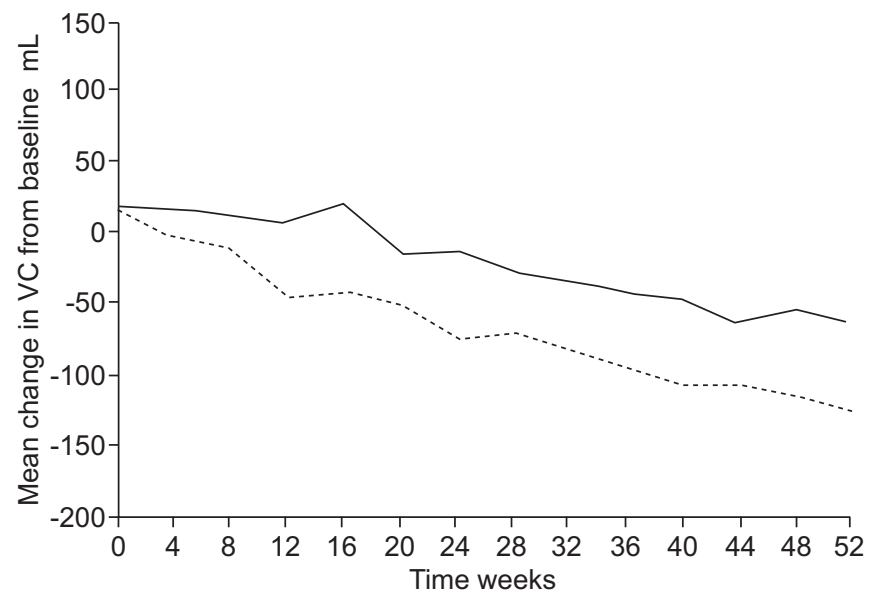

FIGURE 1. Change in vital capacity (VC) at 52 weeks in the Japanese phase II study. —_: pirfenidone $1,800 \mathrm{mg} \cdot$ day $^{-1} ; \cdots \cdots$ : placebo. Relative difference: $44 \%$ $\mathrm{p}=0.042$. 
2,403 $\mathrm{mg} \cdot \mathrm{day}^{-1}$ or placebo in a 1:1 ratio. In both studies, pirfenidone was administered with food three times a day and increased to full dose over 2 weeks. In study 004, the lower dose of $1,197 \mathrm{mg} \cdot$ day $^{-1}$ was included to investigate a potential dose-response effect [38].

The primary end-point of both studies was change in FVC \% pred from baseline to week 72 . The secondary end-points at week 72 for both studies (table 1) included: categorical decline in $\mathrm{FVC} \geqslant 10 \%$; progression-free survival (time to confirmed decline $\geqslant 10 \%$ pred decline in $\mathrm{FVC}, \geqslant 15 \%$ pred decline in DL,CO or death); mean change in 6MWT distance; mean change in $\mathrm{DL}, \mathrm{CO} \%$ pred; mean change in dyspnoea score (using the University of California San Diego Shortness of Breath Questionnaire); mean percentage change in worst $S_{\mathrm{p}, \mathrm{O} 2}$ during $6 \mathrm{MWT}$; and time to worsening IPF (time to acute exacerbation, death, lung transplantation or admission to hospital for respiratory problems). Categorical change in high-resolution computed tomography diagnosed fibrosis was included as a secondary end-point only in study 006. Both studies included mortality as an exploratory end-point [38].

In study 004 , pirfenidone $2,403 \mathrm{mg} \cdot$ day $^{-1}$ significantly reduced mean decline from baseline to week 72 in per cent predicted FVC compared with placebo $(-8.0 \pm 16.5 \%$ versus $-12.4 \pm 18.5 \%$, respectively; $p=0.001)$, as well as the proportion of patients with FVC decline $\geqslant 10 \%$. This treatment effect was evident between weeks 24 and 72 (fig. 2). A pirfenidone effect was confirmed $(p=0.0007)$ after repeated measures analysis of the per cent predicted change in FVC across all assessment timepoints. In the pirfenidone $1,197 \mathrm{mg} \cdot \mathrm{day}^{-1}$ group, the primary end-point outcomes were intermediate to the $2,403 \mathrm{mg} \cdot \mathrm{day}^{-1}$ pirfenidone and placebo groups [38].

Study 006 did not meet the primary efficacy end-point, as there was no significant difference between the pirfenidone and placebo groups in the mean decline in per cent predicted FVC at week $72(-9.0 \pm 19.6 \%$ and $-9.6 \pm 19.1 \%$, respectively) (fig. 2$)$. The difference in FVC outcomes in the two studies might be partly attributable to a lower than expected rate of FVC decline in study 006 after 1 yr. Although the magnitude of decline over time was similar in the two pirfenidone groups, those in the two placebo groups differed [38]. However, the data from this study generally supported those from study 004, with a positive treatment effect of pirfenidone being observed at all time-points from weeks 12 to 48 but not at later time-points [38].

A pirfenidone treatment effect on per cent predicted FVC at week 72 was supported by a pre-specified analysis of the pooled data from both studies $(p=0.005)$. Mean decline in percentage predicted FVC was $-8.5 \%$ and $-11.0 \%$ for the pirfenidone 2,403 $\mathrm{mg} \cdot \mathrm{day}^{-1}$ and placebo groups, respectively (fig. 2). Additionally, the pooled analysis demonstrated a $30 \%$ reduction in the percentage of patients with a categorical decline in FVC $\geqslant 10 \%$ at week $72(\mathrm{p}=0.003)$, a $31 \%$ reduction in the mean decline in 6MWT distance $(p>0.001)$ and a $26 \%$ reduction in the risk of death or disease progression (hazard ratio (HR) $0.74,95 \%$ CI 0.57-0.96; $\mathrm{p}=0.025$ ) (table 1) [38].

Although the study was not powered for mortality analysis, a pooled analysis of the exploratory end-point of mortality revealed that the HRs for all-cause mortality $(p=0.315)$ and mortality related to IPF at any time during the study favoured

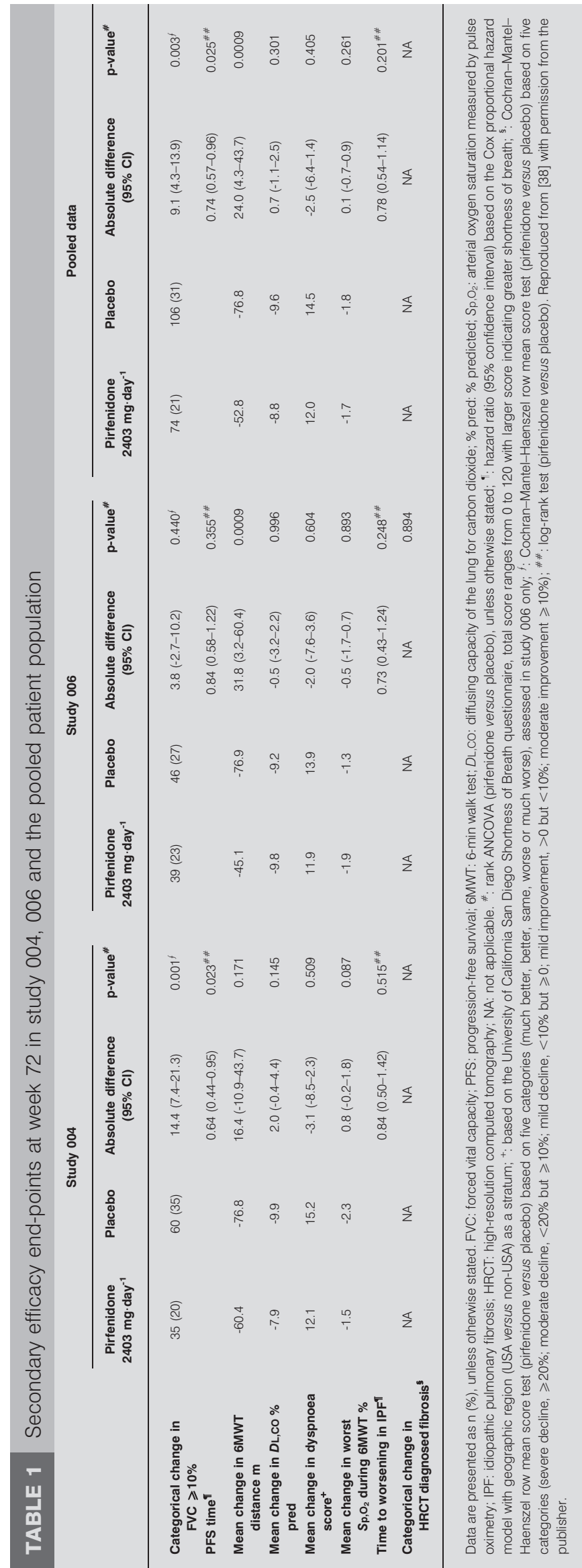



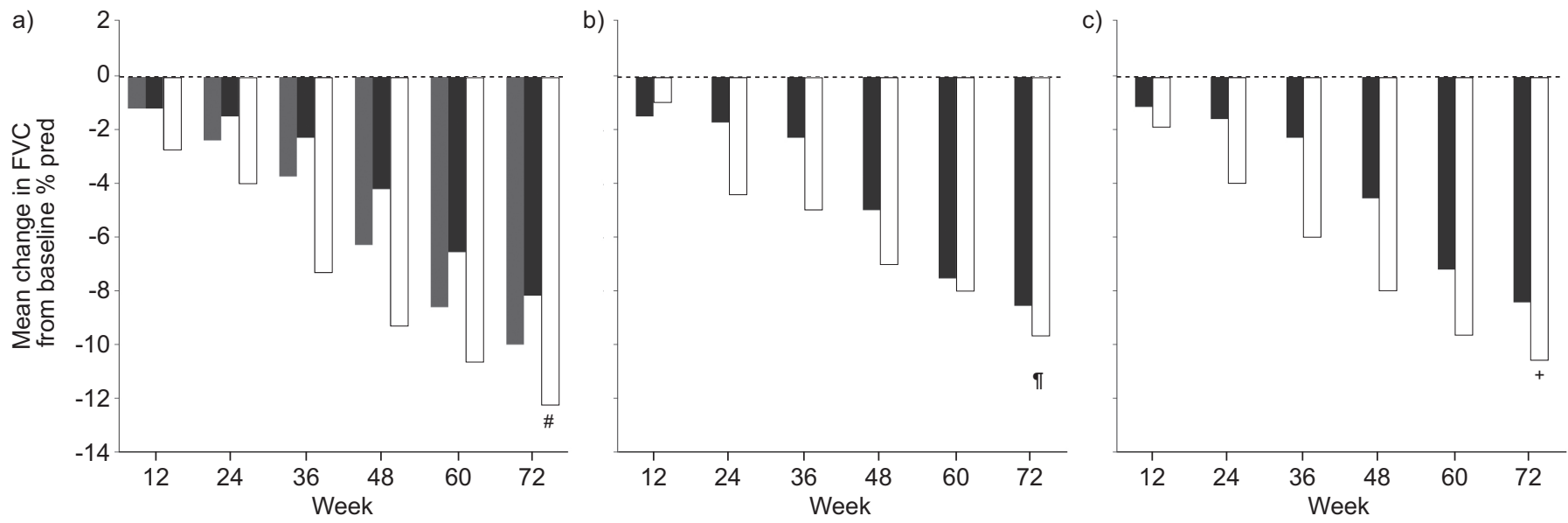

FIGURE 2. Mean change from baseline in per cent predicted forced vital capacity (FVC) in a) study $004, b)$ study 006 and c) the pooled patient population. * : $p=0.001$;

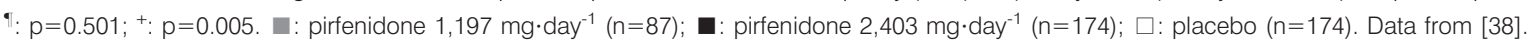

pirfenidone over placebo $(p=0.117)$. This was also the case with on-treatment IPF-related mortality, which occurred in 3\% of patients treated with pirfenidone and $7 \%$ of those given placebo $(\mathrm{p}=0.03)($ table 2$)$ [38].

Pirfenidone was shown to be safe and generally well tolerated at the $2,403 \mathrm{mg} \cdot \mathrm{day}^{-1}$ dose in both studies [38]. There was no significant difference in the number of patients experiencing serious treatment-emergent adverse events between the pooled pirfenidone and placebo groups (33\% and 31\%, respectively) (table 3). Nearly all patients in the pirfenidone $2,403 \mathrm{mg} \cdot$ day $^{-1}$ group (pooled data from both studies) experienced at least one treatment-emergent adverse event, with the most common adverse events being gastrointestinal (nausea 36\%, dyspepsia $19 \%$, vomiting $14 \%$ and anorexia 11\%), skin disorders (rash $32 \%$ and photosensitivity $12 \%$ ) and dizziness (18\%) (table 3 ). These adverse events were consistent with the known safety profile of pirfenidone and were usually mild to moderate in severity [38]. Adverse events led to discontinuation of

\begin{tabular}{|c|c|c|c|c|}
\hline \multirow[t]{2}{*}{ TABLE 2} & \multicolumn{4}{|c|}{$\begin{array}{l}\text { cause and idiopathic pulmonary fibrosis } \\
\text { F)-related mortality in the pooled population }\end{array}$} \\
\hline & $\begin{array}{c}\text { Pirfenidone } \\
2403 \mathrm{mg} \cdot \text { day }^{-1 *}\end{array}$ & Placebo ${ }^{\pi}$ & $\begin{array}{c}\text { Hazard ratio } \\
(95 \% \mathrm{Cl})^{+}\end{array}$ & p-value ${ }^{5}$ \\
\hline \multicolumn{5}{|l|}{ Overall } \\
\hline All-cause mortality & 27 (8) & $34(10)$ & $0.77(0.47-1.28)$ & 0.315 \\
\hline IPF-related mortality & $18(5)$ & $28(8)$ & $0.62(0.35-1.13)$ & 0.117 \\
\hline \multicolumn{5}{|l|}{ On treatment ${ }^{\# \#}$} \\
\hline All-cause mortality & $19(6)$ & $29(8)$ & $0.65(0.36-1.16)$ & 0.141 \\
\hline IPF-related mortality ${ }^{f}$ & $12(3)$ & $25(7)$ & $0.48(0.24-0.95)$ & 0.030 \\
\hline
\end{tabular}

Data are presented as $n(\%)$, unless otherwise stated. ${ }^{\#}: n=345 ;{ }^{\bullet}: n=347{ }^{+}$ based on the Cox proportional hazard model; ${ }^{\varsigma}$ : log-rank test (pirfenidone versus placebo); ${ }^{f}$ : assessed by the investigator, who remained blinded to treatment assignment; ${ }^{\# \#}$ : defined as the time from randomisation until 28 days after the last dose of study drug. Reproduced from [38] with permission from the publisher. treatment in $15 \%$ of the pirfenidone groups and $9 \%$ of the pooled placebo groups. The most common cause for treatment discontinuation was IPF $(3 \%$ both in the pirfenidone and placebo group). The only other causes of treatment discontinuation in the pooled pirfenidone groups were nausea $(1 \%)$ and rash $(1 \%)$. Generally, the most common adverse effects of pirfenidone treatment were manageable by temporary dose modification [38].

TABLE 3 Treatment-emergent adverse events ${ }^{\#}$

\begin{tabular}{|c|c|c|}
\hline Adverse events & $\begin{array}{c}\text { Pirfenidone } \\
2403 \mathrm{mg} \cdot \text { day }^{-1} \text { ब }\end{array}$ & Placebo $^{+}$ \\
\hline Nausea & $125(36)$ & $60(17)$ \\
\hline Rash & $111(32)$ & 40 (12) \\
\hline Dyspepsia & 66 (19) & $26(7)$ \\
\hline Dizziness & $63(18)$ & $35(10)$ \\
\hline Vomiting & $47(14)$ & $15(4)$ \\
\hline Photosensitivity reaction & $42(12)$ & $6(2)$ \\
\hline Anorexia & $37(11)$ & $13(4)$ \\
\hline Arthralgia & $36(10)$ & $24(7)$ \\
\hline Insomnia & $34(10)$ & $23(7)$ \\
\hline Abdominal distension & $33(10)$ & $20(6)$ \\
\hline Decreased appetite & $30(9)$ & $10(3)$ \\
\hline Stomach discomfort & $29(8)$ & $6(2)$ \\
\hline Weight reduction & $28(8)$ & $12(3)$ \\
\hline Abdominal pain & $26(8)$ & $12(3)$ \\
\hline Asthenia & $24(7)$ & $13(4)$ \\
\hline Pharyngolaryngeal pain & $24(7)$ & $16(5)$ \\
\hline Pruritus & $22(6)$ & $14(4)$ \\
\hline Hot flush & $18(5)$ & $4(1)$ \\
\hline
\end{tabular}

Data are presented as $n(\%)$. ${ }^{\#}$ : occurring in $\geqslant 5 \%$ of patients given pirfenidone $2,403 \mathrm{mg} \cdot$ day $^{-1}$ in study 004 or study 006 , and with an incidence 1.5 times higher than that in patients given placebo; ${ }^{\bullet} n=345 ;{ }^{+}: n=347$. Reproduced from [38] with permission from the publisher. 


\section{CONCLUSIONS}

There has been considerable advancement in terms of research into prognostic factors, with decline in percentage of FVC being found to be a predictor of mortality risk. Until recently, therapeutic developments had lagged somewhat, but the increase in the number of clinical trials has been encouraging. However, many of these trials failed to show significant treatment benefit against this challenging disease. Further studies are required to evaluate the potential benefit of NAC and BIBF 1120 in IPF. The first major step forward has been the European approval of pirfenidone for patients with mild-tomoderate IPF. Pirfenidone has demonstrated statistically significant and clinically meaningful effects in clinical trials. Overall, pirfenidone provides a significant treatment benefit for patients with IPF and represents an appropriate option as first-line therapy for these patients.

\section{STATEMENT OF INTEREST}

V. Cottin has received fees for speaking from Intermune, Boehringer Ingelheim and Actelion; and has participated as investigator to clinical trials sponsored by InterMune, Boehringer and Actelion, and as a member of a steering committee for a clinical trial sponsored by Boehringer Ingelheim.

\section{ACKNOWLEDGEMENTS}

I received medical writing assistance from IntraMed Communications (Milan, Italy).

\section{REFERENCES}

1 Hodgson U, Laitinen T, Tukiainen P. Nationwide prevalence of sporadic and familial idiopathic pulmonary fibrosis: evidence of founder effect among multiplex families in Finland. Thorax 2002; 57: 338-342.

2 Orphanet Report Series. Prevalence of rare disease: bibliographic data. Number 1. 2011. www.orpha.net/orphacom/cahiers/docs/ GB/Prevalence_of_rare_diseases_by_alphabetical_list.pdf

3 American Thoracic Society/European Respiratory Society International Multidisciplinary Consensus Classification of the Idiopathic Interstitial Pneumonias. Am J Respir Care Med 2002; 165 : 277-304.

4 Vancheri C, Failla M, Crimi N, et al. Idiopathic pulmonary fibrosis: a disease with similarities and links to cancer biology. Eur Respir J 2010; 35: 496-504.

5 Nathan SD, du Bois RM. Idiopathic pulmonary fibrosis trials: recommendations for the jury. Eur Respir J 2011; 38: 1002-1004.

6 Song JW, Hong SB, Lim CM, et al. Acute exacerbation of idiopathic pulmonary fibrosis: incidence, risk factors and outcome. Eur Respir J 2011; 37: 356-363.

7 Valeyre D. Towards a better diagnosis of idiopathic pulmonary fibrosis. Eur Respir Rev 2011; 20: 108-113.

8 Du Bois RM, Weycker D, Albera C, et al. Six-minute-walk test in idiopathic pulmonary fibrosis test validation and minimal clinically important difference. Am J Respir Crit Care Med 2011; 183: 1231-1237.

9 Du Bois RM, Weycker D, Albera C, et al. Ascertainment of individual risk of mortality for patients with idiopathic pulmonary fibrosis. Am J Respir Crit Care Med 2011; 184: 459-466.

10 Raghu G, Collard HR, Egan JJ, et al. An official ATS/ERS/JRS/ ALAT statement: idiopathic pulmonary fibrosis: evidence-based guidelines for diagnosis and management. Am J Respir Crit Care Med 2011; 183: 788-824.

11 Flaherty KR, Mumford JA, Murray S, et al. Prognostic implications of physiologic and radiographic changes in idiopathic interstitial pneumonia. Am J Respir Crit Care Med 2003; 168: 543-548.
12 Du Bois R, Albera C, Bradford W, et al. Percent predicted forced vital capacity (FVC) is a reliable, valid, and responsive measure of clinical status in patients with idiopathic pulmonary fibrosis (IPF). Eur Resp J 2010; 36: Suppl. 54, 646s.

13 Collard HR, King TE Jr, Bartelson BB, et al. Changes in clinical and physiologic variables predict survival in idiopathic pulmonary fibrosis. Am J Respir Crit Care Med 2003; 168: 538-542.

14 King TE Jr, Safrin S, Starko KM, et al. Analyses of efficacy end points in a controlled trial of interferon- $\gamma 1 b$ for idiopathic pulmonary fibrosis. Chest 2005; 127: 171-177.

15 Latsi PI, du Bois RM, Nicholson AG, et al. Fibrotic idiopathic interstitial pneumonia: the prognostic value of longitudinal functional trends. Am J Respir Crit Care Med 2003; 168: 531-537.

16 Hallstrand TS, Boitano LJ, Johnson WC, et al. The timed walk test as a measure of severity and survival in idiopathic pulmonary fibrosis. Eur Respir J 2005; 25: 96-103.

17 Lederer DJ, Arcasoy SM, Wilt JS, et al. Six-minute walk distance predicts waiting list survival in idiopathic pulmonary fibrosis. Am J Respir Crit Care Med 2006; 174: 659-664.

18 Swigris JJ, Swick J, Wamboldt FS, et al. Heart rate recovery after 6min walk test predicts survival in patients with idiopathic pulmonary fibrosis. Chest 2009; 136: 841-848.

19 Caminati A, Bianchi A, Cassandro R, et al. Walking distance on 6MWT is a prognostic factor in idiopathic pulmonary fibrosis. Respir Med 2009; 103: 117-123.

20 Costabel U. Emerging potential treatments: new hope for idiopathic pulmonary fibrosis patients? Eur Respir Rev 2011; 20: 201-207.

21 Demedts M, Behr J, Buhl R, et al. High-dose acetylcysteine in idiopathic pulmonary fibrosis. $N$ Engl J Med 2005; 353 2229-2242.

22 NIH News. Commonly used three-drug regimen for idiopathic pulmonary fibrosis found harmful. October 21, 2011. http:/ / public nhlbi.nih.gov/newsroom/home/GetPressRelease.aspx?id=2812

23 Wells AU, Behr J, Costabel U, et al. Triple therapy in idiopathic pulmonary fibrosis: an alarming press release. Eur Respir J 2012; 39: 805-806.

24 Richeldi L, Costabel U, Selman M, et al. Efficacy of a tyrosine kinase inhibitor in idiopathic pulmonary fibrosis. $N$ Engl J Med 2011; 365: 1079-1087.

25 King TE, Behr J, Brown KK, et al. BUILD-1: a randomized placebocontrolled trial of bosentan in idiopathic pulmonary fibrosis. Am J Respir Crit Care Med 2008; 177: 75-81.

26 King TE, Brown KK, Raghu G, et al. BUILD-3: a randomized, controlled trial of bosentan in idiopathic pulmonary fibrosis. Am J Respir Crit Care Med 2011; 184: 92-99.

27 Daniels CE, Lasky JA, Limper AH. Imatinib treatment for idiopathic pulmonary fibrosis: randomized placebo-controlled trial results. Am J Respir Crit Care Med 2010; 181: 604-610.

28 Zisman DA, Schwarz M, Anstrom KJ, et al. A controlled trial of sildenafil in advanced idiopathic pulmonary fibrosis. $N$ Engl J Med 2010; 363: 620-628.

29 Raghu G, Brown KK, Costabel U, et al. Treatment of idiopathic pulmonary fibrosis with etanercept: an exploratory, placebo-controlled trial. Am J Respir Crit Care Med 2008; 178: 948-955.

30 King TE, Albera C, Bradford WZ, et al. Effect of interferon gamma$1 \mathrm{~b}$ on survival in patients with idiopathic pulmonary fibrosis (INSPIRE): a multicentre, randomised, placebo-controlled trial. Lancet 2009; 374: 222-228.

31 Schaefer CJ, Ruhrmund DW, Pan L, et al. Antifibrotic activities of pirfenidone in animal models. Eur Respir Rev 2011; 20: 85-97.

32 Iyer SN, Gurujeyalakshmi G, Giri SN. Effects of pirfenidone on transforming growth factor-beta gene expression at the transcriptional level in bleomycin hamster model of lung fibrosis. J Pharmacol Exp Ther 1999; 291: 367-373. 
33 Gurujeyalakshmi G, Hollinger MA, Giri SN. Pirfenidone inhibits PDGF isoforms in bleomycin hamster model of lung fibrosis at the translational level. Am J Physiol 1999; 276: 311-318.

34 Iyer SN, Gurujeyalakshmi G, Giri SN. Effects of pirfenidone on procollagen gene expression at the transcriptional level in bleomycin hamster model of lung fibrosis. J Pharmacol Exp Ther 1999; 289: 211-218.

35 Oku H, Shimizu T, Kawabata T, et al. Antifibrotic action of pirfenidone and prednisolone: different effects on pulmonary cytokines and growth factors in bleomycin-induced murine pulmonary fibrosis. Eur J Pharmacol 2008; 590: 400-408.
36 Azuma A, Nukiwa T, Tsuboi E, et al. Double-blind, placebocontrolled trial of pirfenidone in patients with idiopathic pulmonary fibrosis. Am J Respir Crit Care Med 2005; 171: 1040-1047.

37 Taniguchi H, Ebina M, Kondoh Y, et al. Pirfenidone in idiopathic pulmonary fibrosis. Eur Respir J 2010; 35: 821-829.

38 Noble PW, Albera C, Bradford WZ, et al. Pirfenidone in patients with idiopathic pulmonary fibrosis (CAPACITY): two randomised trials. Lancet 2011; 377: 1760-1769.

39 Raghu G, Johnson WC, Lockhart D, et al. Treatment of idiopathic pulmonary fibrosis with a new antifibrotic agent, pirfenidone. Am J Respir Crit Care Med 1999; 159: 1061-1069. 